\title{
THE INTERACTIVE DESIGN EXPERIENCE OF RESPONSIVE INTERIOR ARCHITECTURE AND ITS IMPACT ON THE CULTURE OF THE RECIPIENT
}

\author{
Fayza Mohamed Ahmed AL-DALAL *
}

Decoration Department, Faculty of Fine Arts, Alexandria University, Egypt

\begin{abstract}
The existence of a building that reflects the technological and cultural conditions of our time and respects the environment in it is a goal pursued by the pioneers of responsive architecture, which spread with the late sixties of the last century by the architect Nicolas Negroponte, who sought through his architecture to integrate automatic control devices in his buildings for the existence of an architecture interacting with its residents ; This type of architecture and its internal spaces that developed day after day with the emergence of what is known as the Internet of things, smart systems, building automation and digital interaction of the elements and vocabulary of interior design responding to the multiple variables of the surrounding nature and the needs of its inhabitants; Which made it a unique design experience for them, which obligated them accordingly to the existence of a new type of culture in dealing with this new vocabulary, which requires a degree of flexibility, adaptability and continuous change. These buildings provide the recipient with an internal space that is compatible with his community and his environment, and this depends on the extent of efficiency in the use of this new technology that deals with the surrounding climatic, geographical, historical and social conditions, this interior architecture that uses environmentally friendly materials and natural energies, which in turn led to the existence of the so-called safe space It is sanitary for its use, which depends on lighting and natural ventilation. There is also the integration of computing energy into built spaces and structures, which measure the actual environmental conditions through remote sensing devices to enable buildings to adapt their shape, color and character according to those conditions to become an integral part of life inside the building and thus these devices have a strong role in terms of symbolic and dramatic expression. Within the space, the recipient shares life and the recipient shares his continuous changes. Thus, the research is an attempt to integrate the environmental component into the internal design process in order to develop new environmental policies based on environmental economics and sustainable development, which is the seventeenth axis "The axis of environment and the protection of natural resources" within the science strategic projects and studies Technology and innovation 2030 for the sustainable development of our beloved Egypt. Key words: sustainability, smart systems, building automation, digital interaction, zero neutrality.

Keywords

Design Experience, Interior Architecture, The Culture, The Recipient.
\end{abstract}

\section{Introduction}

Stuart Brand confirms in his book How Buildings Learn. How Buildings Learn "Responsive architecture is an advanced field that measures actual environmental conditions (via sensors) to enable buildings to adapt to the climate and human environment through the computing power embedded in the building structures, and provides the integration of these responsive components into the architecture and design of their spaces. The interior is the ability to enhance the building experience by expressing transient and changing aspects of the environment in an architectural work of cultural significance.

Therefore, this thesis examines the different perspectives on the relationships between man and

*Corresponding author: finea-dean@alexu.edu.eg 
the environment, leading to what is known as responsive internal architecture, which caused the environment to change in its vocabulary, raw materials and the technology used with it, and therefore the design idea of the internal space of this architecture, where the attempt to link this space and the surrounding environment through a frame My knowledge is based on a descriptive and analytical approach with a presentation of many models that refer to the spatial reaction through the design process; These design trends came to try to build a common environment between humans and the environment through feedback represented by the following three factors:

Climatic environmental factors, social factors and economic "ethnographic analysis" of the client; Which explains the effective participation of the designer's vocabulary in the design process. Hence the importance of research in showing different design solutions to the nature of the responsive space and how to integrate these design vocabulary and tools in the environmental context, which are based on the recipient, the unity of building society and the environment, through the following points:

\section{- Interior design, technological and cultural conditions:}

Responsive architecture and interior design, "Responsive design, units of space, and the Internet of Things."Interior space responsiveness as a sustainable solution to the design process.

-Design response to the neutral space carbon (transponder footprint).

-Responding by deleting and adding to the determinants of the internal space, "The response of the internal architecture of human life, the economy and the function of space".

\section{- Interior design, technological and cultural conditions:}

The designer, Thomas Mitchell, "Professor at Indiana University - USA" asserts that the design must present a comprehensive new theory of design where the user's needs are the basis of this design process, and this design work focuses on the design in terms of human experience rather than the physical form. It is since modernity, late modernity, postmodernism and deconstruction that does not fit its design purpose; Not because of its style but because of the design process itself, then Mitchell reviews the design methods that the user responds to, which he describes as the design that is transformed inward, which is concerned with collaborative, contextual and invisible design in terms of the language of the style and design based on the will of man, which paves the way for the existence of a redefinition of design that combines Architects, planners and landscape architects, in addition to interior architecture designers and manufacturers, and this is what the current era is witnessing in terms of the overlap of many 
technologies in the design process. The harsh transformation that the design process is currently witnessing "is a turning point from the use of simple digitization and to innovation that is based on A combination of technologies that push companies to rethink the way they do business, such as automation, which is a mixture of algorithms, and symbolic forms, which digitally transform all kinds of jobs and industries. Relationships that will change what we do, will affect who we are and all related matters. In it, intellectual property concepts, consumption patterns, the time we devote to work and leisure will change, and how we develop our work and Developing our design skills, in addition to that these design trends will change our health and take us towards a quantum self. "The list does not end because nothing is limited by our imagination and which redefines the meaning of humanity by extending the rates of life, health, perception, which will force us to redefine our knowledge which There will be a new meaning for the interior design process.

\section{Responsive Architecture and Interior Design:}

\section{1- Design response and space modules:}

Responsive Interior Architecture is one of the evolving areas in the interior design process and subsequently in the field of architectural research. These are those that enable internal space to adapt via sensors, and aim to improve architecture by improving the energy performance of buildings with responsive technologies such as sensors, control systems and actuators; With the production of buildings that reflect the technological and cultural conditions of our time, and making them interactive buildings by integrating smart technologies Responsive in the basic elements of building texture, and this enables designers to re-examine the way in which they design and create the interior space, Nicholas Negroponte introduced the term "responsive architecture", who first invented it in the late 1960s when spatial design problems were being explored. By applying cybernetics to architecture, he found that those buildings were better performing and more rational.

Numerous design works have emerged afterwards that monitor fluctuations in the environment and alter the shape of its interior spaces in response to these changes. While a great deal of time and effort has been spent on smart homes in recent years, the focus here has been mainly on developing electronic systems to adapt the interior spaces of the building according to the residents 'needs and their ability to adapt to changing weather conditions and take into account light, heat and cold, certified On the capabilities of computers to compute and consistently join digital programmable forms.

This change may be sudden and unexpected as a result of the response of the building and its internal spaces to the environment and the needs of its inhabitants. Buildings are fixed, but 
most buildings also contain equipment that allows a greater degree of suitability "to changing conditions." Le Corbusier used the term "household equipment" to refer to furniture as well as disposable items. To this list, we can now add the mechanical parts of the building that allow internal spaces to be adapted, such as windows, doors, movable barriers, operable openings, sunshades, screens, etc., and this is the result of the tremendous developments in artificial intelligence and miniaturization of components that will lead to Creating buildings capable of intelligently recognizing these changes in the external and internal environment, and the rate at which these changes are made provides another way to describe and classify the types of responsive internal structure.

The designer, Cedric Price, whose building spaces appeared "Fun Palace" is able to adapt to the needs of its users. Which appeared as an architectural experiment that had a strong impact on the art of "hi-tech" architecture, which in turn created many responsive designs such as the Center Georges Pompidou (18 AD) by Renzo Piano and Richard Rogers in Paris, which follows the spirit of the fun palace with its visual expression in the application of bone and skin theory in construction In fact, all the components and spaces of the building appeared in a state of constant change and were innovative in its time, and the suggestion of rates of change as a basic organization had a principle for building components. The designer, Stuart Brand, believes that due to the different rates of change Environmental components, the building always tears itself according to its "response." Hence the concept of interactive surfaces as an expressive element of the building in many facilities, such as an interactive acoustic surface with integrated electromagnetic wires, touch sensors, and pneumatic structures with integrated display screens. They are surfaces that glow in response to ambient noise levels Try to isolate the internal space from the outside noise.

\section{2- Design Response and the Internet of Things:}

The response of the building and its spaces is not only in the units of space, its technologies, and the technology that follow, but there is the Internet of Things (IoT), which is a network of physical devices, household appliances and other electronic elements, computers, sensors, motors and communication that enable these devices to Communication and data exchange, everything is uniquely defined by a computer system capable of interacting within a space infrastructure.

The term (loT) that was first proposed by the British "Kevin Ashton", this system that provides opportunities for more direct integration of the physical world into computer-based systems with physical objects such as devices and tools in homes and markets for example, and what helped spread this term was the presence of technologies Modern technology helped to 
implement it on the ground such as radio frequency technology (RFID), remote sensors and barcode (Barcode), all these technologies became the process of integrating or connecting them with the Internet, such as smart checks, virtual power stations and smart homes that use their devices (Wi - Fi) for remote monitoring, smart transportation and smart cities leading to improved efficiency, accuracy and economic benefit in addition to reducing human interference and representing interconnection between networks and devices in the digital age. As for the more mature form, it is that the different "things" interact with each other using the Internet protocol. The characteristic of artificial intelligence and machine computing should be mentioned here, so that it simulates human intelligence as much as possible.

Sam Lyucero, an analyst at the ABI Research Center in New York, says that anything smart will have a presence on the Internet of things. "And Dave Evans, a futurist, agrees with this saying, and he expects that there will be 50 billion connected devices by the year 2020 . Social networks perform this connection. The model includes the concept of the triple universe, which consists of the physical world, the virtual world, the mental world, and a multi-level reference architecture with nature and devices at the bottom level, followed by the level of the Internet, the sensor network, the mobile network, and the intelligent communities of human machines on the higher level, says Kevin Dallas Microsoft director said that the design of commercial spaces will take a new step in the design process. When dealing with the customer (and he was a member of the loyalty program of a store) and sending him the shopping list to the store and after identifying the identity wirelessly, "RFID", a digital display device signals Follow the network by directing the customer through the different corridors, from one commodity to another, to find what the customer wants according to what he sent from a shopping list; these signals also take the customer's metrics when approaching the Promotions that are meant to be sized for clothing are displayed; This thus creates a new definition of the internal design process of a commercial space and the designer's vocabulary used.

In the healing spaces, the internal space will appear in a new way in which the advanced medical devices will appear as an important design unit within the space and not complementary to the space, such as pacemakers and hearing devices. Some hospitals have started to use "smart beds, which can determine if beds are vacant, and can also be used to check if the patient is trying to get up. They can also adjust themselves to ensure proper pressure and provide support to the patient. Sensors can also monitor the condition." Sanitary devices for the elderly in living rooms Other wireless devices can encourage the user to live a healthy life, such as wearable heart monitors, and there are many other health monitoring platforms. As for residential areas after home automation, it is the future view of it through the Internet of 
things, with centralized control of all its devices. The recipient of the space can condition the air through a smart phone, and the residential space can be converted into an environmentally friendly space such as lighting lamps and electronics automatically, and the environmental monitoring applications of the Internet of Things usually use sensors to help protect the environment by monitoring the quality of air or water, and Internet devices can also be used. Objects in the monitoring and control of mechanical, electrical and electronic systems used in different types of buildings, as well as assisting the elderly in medical emergencies such as falls or seizures through sensors. The first of these applications was in November 2013 AD in the internal spaces of Alzheimer's patients - Los Angeles, where their steps inside the space were linked to an electronic system that sends signals to the Internet of things, and if the patient steps away from the path of the path specified for him outside the space he sends warnings to his family and that the patient is in Danger, this technology that has been spreading now "in many walks of life, such as the energy sector, and various utilities, and this is what was mentioned by Computer World electronic magazine.

- Results:

1- The necessity for sustainable and economic shelter is stronger than ever. Lifestyles and daily routines also change, which requires a new internal space in terms of thought and form.

2- Re-imagining the internal space as a robotic machine is also a rethinking of the design process as a response to the daily patterns of life by virtue of the conceptual and practical distinction between the elements responsive to the building and the size of the structure.

3- Responsive design provides the user with ways to assess their needs before starting the design, as the user's requirements guide the design process, and measure the project's success in the extent of the design's ability to meet the needs of users.

4- Responsive space is the ideal resource and inspiration for designers, architects, builders and for any recipient looking to maximize living space with minimal environmental impact.

5- The interior design of the current and future interior architecture is difficult to distinguish between rooms and their furniture. Where the urgent need for continuity between architectural design and design of space elements, which are closer to pieces of equipment than furniture. It shapes the nature of a designer's future work.

6- It has become possible to harness communication and information technologies to bring about huge technical revolutions, and the technology of Internet things. And the near 
future will bring us many surprises about this modern technology, for more comfort and ease in all matters of human life.

7- Things communicate and understand each other without human intervention in the era of the Internet of things, and this requires a great change and requires a great role from sociologists, psychologists, designers and architects.

8- Digital design tools, sustainable materials, and new manufacturing techniques, a design method for small homes with "Nano Living Systems" in terms of climatic and environmental contexts, building methods, and spatial innovations.

9- The presence of pre-fabricated buildings helps to reduce costs by $20 \%$ and reduce delivery time by $50 \%$ or more.

10- With the spread of "loT" technology, the volume of data that will be generated will be thousands of times what it is now. Therefore, it requires the designer to learn more skills such as computers and how to deal with smart systems and the existence of many legislations, and for this this decision needs to formulate a general policy on the Internet of Things and the issue of privacy and security, as the Congress has already done in its decision, which was passed by the Council The sheikhs in March 2013 AD and in March 2014 AD, when a bill was proposed to develop innovation and the growth of the Internet of Things. Therefore, the research recommends the necessity of the existence of many scientific researches dealing with the Internet of things calling for more direct integration of computer-based systems with design vocabulary and sensors and their integration. With the Internet, a new future space came out of it.

11- The age of the Internet of Things requires the governments of developing countries to expand the strengthening of the Internet infrastructure.

\section{Recommendations:}

1- The research recommends the need for a neutral, zero-carbon space, with the necessity for the designer to go to industrial production and 3D printing, and alternative building methods today such as passive homes show that building design can achieve savings in thermal energy and cooling by up to $20 \%$, with a higher average investment rate Only $10 \%$ of the traditional building. Most of the three-dimensional, alternative building methods today, such as passive homes, show that building design can achieve thermal energy and cooling savings of up to $90 \%$, with an average investment only $10 \%$ higher than traditional building. Most buildings can be positive energy, and move from being energy-consuming and producing energy that can move from the spaces of these buildings to buildings and energy gathering stations through networks of the Internet of 
Things.

2- The research recommends the necessity of having curricula taught within the College of Fine Arts, especially the specialization of Architecture and Interior Architecture, which contains how the design process responds to the technological conditions in the era, such as sustainable smart systems for space and its continuity with Internet of things technologies and the control of design vocabulary remotely through wireless communication means, for example., Which thus builds a "designer" student who is compatible with his environment, his community and his age.

\section{References :}

1- Adrian Devaun Smith, Gordon Gill. Toward Zero Carbon: The Chicago Central Area DE carbonization Plan. Images Publishing, ISBN: 1864704330, 9781864704334. 2011. 2- Alfredo Andia, Thomas Spiegelhalter. Post-Parametric Automation in Design and Construction. Artech House, ISBN: 1608076946, 9781608076949.2014.

3- BK Tripathy, J Anuradha. Internet of Things (IoT): Technologies, Applications, Challenges and Solutions. CRC Press, ISBN: 1351980297, 9781351980296.2017.

4- C. Thomas Mitchell, Redefining Designing: From Form to Experience. Wiley, ISBN: 0471290815, 9780471290810. 1992.

5- C. Thomas Mitchell, Jiangmei Wu. Living Design: The Daoist Way of Building. McGraw-Hill, ISBN: 0070429758, 9780070429758.2007.p.107

6- Jay Shafer. Jay Shafer's DIY Book of Backyard Sheds \& Tiny Houses: Build Your Own Guest Cottage, Writing Studio, Home Office, Craft Workshop, or Personal Retreat. Fox Chapel Publishing, SBN: 1607651238, 9781607651239.2013.

7- Joanna Williams. Zero-carbon Homes: A Road Map. Routledge, ISBN: 1136575545, 9781136575549. 2013.

8- Mark Lawson, Ray Ogden, Chris Goodier. Design in Modular Construction. CRC Press ISBN: 0203870786, 9780203870785.2014. P.9.

9- Management Association, Information Resources. The Internet of Things: Breakthroughs in Research and Practice: Breakthroughs in Research and ractice. IGI Global, ISBN: 1522518339, 9781522518334.2017.

10- Mohamed A. Suleiman, Muhammad S. Al-Rashidi, Hani G. Mohamed, Building of International Company of the Suez Canal Marine, Port Said City (Architectural Innovation Design of $19^{\text {th }}$ Century), International Journal of Architectural Engineering and Urban Research, Vol. 1, No. 1, 2018, pp. 13-19.

11- Martin Godrey Cook. The Zero-Carbon House. Crowood, ISBN: 1847973310, 
9781847973313. 2011.

12- Rajkumar Buyya, Amir Vahid Dastjerdi.Internet of Things: Principles and Paradigms. Elsevier, ISBN:0128093471, 9780128093474. 2016.

13- Richard Hyde. Climate Responsive Design: A Study of Buildings in Moderate and Hot Humid Climates.

14- Iman Ali Rushdi El-Hawary, Architectural Vocabulary as Inspirational Elements of Multi-Purpose Design Courses (Case Study of Forms and Models Cours in the Department of Interior Design, Taibah University), International Journal of Architectural Engineering and Urban Research, Vol. 1, No. 2, 2018, pp. 18-21.

15- Taylor \& Francis, ISBN: 0419209700, 9780419209706.2000.

16- Takeshi Yao. Green Energy and Technology ,Zero-Carbon Energy Kyoto 2011: Special Edition of Jointed Symposium of Kyoto University Global COE "Energy Science in the Age of Global Warming" and Ajou University. BOOK 21.

17- Springer Science \& Business Media, ISBN: 4431540679, 9784431540670.2012.

18- https://doi.org/10.1016/j.foar. 2015.03.002 Get rights and content

19- http://pictify.saatchigallery.com/1186732/the-jewish-museum-pierre-chareaumodern-architecture-anddesign.

20- Mai Abdel-Hamid Abdel-Malek Ali And Yamani Muhammad Fathallah, Ffice Buildings Interior Design Through Visual Identity, International Journal of Architectural Engineering and Urban Research, Vol. 2, No. 1, 2019, pp. 26-37.

21- https://ar.wikipedia.ora/wiki/\%D8\%A5\%D9\%86\%D8\%A\%D8\%B1\%D9\%86\%D8\% AA\%D8\%A7\%D9\%84\%D8\%A3\%D8\%B4\%D9\%8A\%D8\%A7\%D8\%A1

22- http://archive.aawsat.com/details.asp? section=13\&article $=653060 \&$ issueno $=12061 \#$. W9vwrtlzbcc

23- https://inhabitat.com/worlds-smallest-sustainable-house-can-accommodate-a-familyof-four/nanoliving-system-1

24- https://www.nanolivingsystem.com/renewable-energy-solutions-1

25- https://www.nanolivingsystem.com/nano-composite-wall-1

26- http://www.zerocarbonhub.org/zero-carbon-policy/zero-carbon-policy

27- https://www.treehugger.com/sustainable-productdesign/what-is-a-zero-carbonhome.html

28- https://www.motherearthliving.com/mother-earth-living/how-to-build-zero-carbonhome

29- https://www.treehugger.com/sustainable-product-design/experimental-zero-carbon- 
development-isantithesis-of-eco-bling-video.html

30- https://www.treehugger.com/green-architecture/architecture-2030-goes-after-

embodied-carbon-andvery-big-deal.html

31- http://sillysidilly.wordpress.com/2008/07/07/pointing-a-cardboard-fi nger/

32- https://evdsseniorstudio.files.wordpress.com/2011/10/emergency-housing.pdf

33- http://www.ericwestonphoto.net/danburry-good-interior-design

34- https://en.wikipedia.org/wiki/Tiny house movement\#cite ref-:1 24-0

35- https://en.wikipedia.org/wiki/Tiny house movement\#cite ref-:1 24-0

36- https://www.treehugger.com/green-architecture/ufogel-austrian-micro-house-forrent.html

37- https://en.wikipedia.org/wiki/Mobile home\#/media/File:Manufactured Home Roof ls Built And Lifte d In Place.jpg

38- https://en.wikipedia.org/wiki/Mobile home\#/media/File:Pine Grove Homes Interior Side Walls Are Attached.jpg

39- https://detours.canal.fr/maison-livrable-clef-main-nimporte

40- https://www.wernick.co.uk/new-wernick-modular-building-system

41- https://en.wikipedia.org/wiki/Modular design

42- https://en.wikipedia.org/wiki/OpenStructures

43- https://en.wikipedia.org/wiki/Modularbuilding\#/media/File:Stoke newington raines court 1.jpg

44- https://fora2016.wordpress.com/

45- https://www.portakabin.co.uk/gb-rowing.htm

46- C. Thomas Mitchell. User-responsive Design: Reducing the Risk of Failure. Norton, ISBN: 0393731057, 9780393731057.2002 -Jorge Otero-Pailos. Architecture's Historical Turn: Phenomenology and the Rise of the Postmodern. U of Minnesota Press, ISBN: 1452942692, 9781452942698. 2013.

47- Sravani Bhattacharjee. Practical Industrial Internet of Things Security: A practitioner's guide to securing connected industries. Packt Publishing Ltd, ISBN: 1788830857, 9781788830850.2018 .

48- https://en.wikipedia.org/wiki/Tinyhouse_movement\#cite_ref-:1_24-0

49- https://evdsseniorstudio.files.wordpress.com/2011/10/emergency-housing.pdf

50- https://en.wikipedia.org/wiki/Friggebod

51- http://greenupgrader.com/2387/recycled-pallet-house-disaster-relief-housing/

52- https://en.wikipedia.org/wiki/Modular_design 
53- https://www.treehugger.com/green-architecture/six-ways-transform-builtenvironment.html

54- https://en.wikipedia.org/wiki/Mobile home

55- https://www.treehugger.com/green-architecture/architecture-2030-goes-afterembodied-carbon-and-very-bigdeal.html

56- https://en.wikipedia.org/wiki/Mobilehome\#/media/File:Mobilehome transport.jpg

57- http://www.reactionhousingsystem.com/

58- https://en.wikipedia.org/wiki/Mobilehome\#/media/File:Modern desert mobile home manufactured house.jpg

59- https://en.wikipedia.org/wiki/Mobile home\#/media/File:Manufactured Home Ready For Shippment To Your Site.jpg

60- https://en.wikipedia.org/wiki/Mobile home\#/media/File:Pine Grove Homes Ready For Drywall.jpg

61- https://en.wikipedia.org/wiki/Mobile home\#/media/File:Pine Grove Homes Interior Side Walls Are Attached.jp

62- https://en.wikipedia.org/wiki/Mobile_home

63- https://www.treehugger.com/sustainable-product-design/experimental-zero-carbondevelopment-is-antithesis-of-1 eco-bling-video.html

64- https://en.wikipedia.org/wiki/Modular_building\#/media/File:Ready_for_shipping.jpg

65- http://www.zerocarbonhub.org/zero-carbon-policy/zero-carbon-policy

66- http://www.lowcarbonlivingcrc.com.au/news/news-archive/2018/10/zero-energyhome-kick-starts-218-millionenergy-efficiency-pilot-program.

Received: February 25, 2019

Accepted: April 10, 2019 